\title{
Microbiological Quality and Safety of Minas Frescal Cheese Commercialized Under Federal Inspection in Rio de Janeiro City, RJ, Brazil
}

Camilla Pires de Souza (I), Luis Eduardo Henrique de Freitas

Pereira (I), Karen Signori Pereira (I)

(I) UFRJ - Universidade Federal do Rio de Janeiro (Av. Athos da Silveira Ramos, 149. Bloco E Ilha do Fundão, RJ, Brasil)

\section{Resumo}

Minas frescal cheese is the most popular soft cheese consumed in Brazil. However, faults in cheese making process from raw material to final product storage can lead to contamination by pathogenic microorganisms. The ingestion of cheeses in inadequate hygienic conditions may cause serious risks for population becoming a public health problem. In order to evaluate the microbiological quality and safety of Minas frescal cheese commercialized in Rio de Janeiro city it was performed an analysis of pathogenic bacteria coagulase-positive Staphylococcus spp. and Salmonella spp., as well as of the indicator microorganisms of fecal contamination Escherichia coli, and it was made a verification of the possible presence of staphylococcal enterotoxins (SEs). Thirty-six cheeses samples belonging to three lots of four brands (A, B, C and D) with registration at the Federal Inspection Service were submitted to microbiological analysis according to the methodology recommended by the American Public Health Association (APHA). All cheese samples were also analyzed for the presence of classical enterotoxins (SEA, SEB, SEC ${ }^{1,2,3}$, SED and SEE) by VIDAS SET II immunoassay. The results demonstrate contamination in 38,9\% of analyzed cheeses belonging to brands A, C and D. In two cheeses samples of brand A were isolated coagulase-positive Staphylococcus spp. - with $7,4 \times 10^{3}$ and $2,7 \times 10^{3} \mathrm{CFU} / \mathrm{g}$ counts - above the maximum acceptable value recommended by Brazilian legislation. Brands $\mathrm{C}$ and $\mathrm{D}$ showed the 
presence of E. coli - in $88,9 \%$ and $44,4 \%$ of analyzed cheeses, respectively - with counts ranging from $2,5 \times 10^{3}$ to $1,3 \times 10^{5} \mathrm{CFU} / \mathrm{g}$. Salmonella spp. and staphylococcal enterotoxins were not detected in cheeses samples.

Although the number of contaminated samples was low, these results indicate contamination found flaws in the manufacturing practices of food, which cause concerns about food safety and demonstrates the importance of maintaining rigorous system of quality control in dairy products.

Palavras-Chave: Coagulase-positive Staphylococcus spp., Escherichia coli, Microbiological quality and safety, Minas frescal cheese, Salmonella spp.

Agência de Fomento: National Council for Scientific and Technological Development (CNPq) 